\title{
GEOPOLYMERS SYNTHESIZED FROM PHILIPPINE COAL ASH AS SUSTAINABLE ALTERNATIVE LOW HEAT TRANSMISSION AND FIRE-RESISTANT MATERIAL FOR BUILDINGS
}

\author{
Martin Ernesto Kalaw ${ }^{1}$, Joshua Martin Kalaw ${ }^{2}$, and Michael Angelo Promentilla ${ }^{2}$ \\ ${ }^{1}$ Mechanical Engineering Department, Gokongwei College of Engineering, De La Salle University, Manila, \\ Philippines, Tel. +632 85244611, e-mail: martin.kalaw@dlsu.edu.ph \\ ${ }^{2}$ Chemical Engineering Department, Gokongwei College of Engineering, De La Salle University, Manila, \\ Philippines, Tel. +632 85244611, e-mail: michael.promentilla@dlsu.edu.ph
}

Received Date: August 5, 2020; Revised Date: January 13, 2021; Acceptance Date: March 5, 2021

\begin{abstract}
Geopolymers are formed from alumina and silica rich materials by alkali dissolution and subsequent polycondensation into a polymeric network. Geopolymerization technology presents a great potential for positive environmental impact since many alumina- and silica- rich industrial waste materials, such as coal ashes, blast furnace slags, mine tailings, etc., can be used as its precursor materials in a process that requires less energy and gives up less emissions vis-à-vis the current conventional OPC (ordinary Portland cement) technology. In this study, geopolymer samples were prepared using an $85 \%$ coal fly ash (CFA) - $10 \%$ coal bottom ash (CBA) - 5\% rice hull ash (RHA) wt/wt mix proportion and activated using an alkali solution of $\mathrm{NaOH}-\mathrm{Na}_{2} \mathrm{SiO}_{3}$ at an $80 \%-20 \% \mathrm{wt} / \mathrm{wt}$ solid-to-liquid ratio. With this mix proportion, two types of specimens were used, a slab type with $50 \mathrm{~mm}$ thickness, and a cube type, $50 \mathrm{~mm} \times 50 \mathrm{~mm}$ x $50 \mathrm{~mm}$. The slab type specimens were used for evaluating fire resistance using ASTM E119, Standard Test Methods for Fire Tests of Building Construction and Materials, and the cube type specimens were used to study the effect of foaming agents on the strength and thermal conductivity of the geopolymers formed. Two types of foaming agents, hydrogen peroxide and sodium perborate, at an amount of $0.1 \%$ to $0.4 \%$ of dry mass mixture, were used. Results from the foamed geopolymers gave compressive strength values ranging from 0.37 to $0.71 \mathrm{MPa}$ and densities of $1430-1560 \mathrm{~kg} / \mathrm{m}^{3}$ at $0.3 \%$ to $0.4 \%$ peroxide added. Values of thermal conductivity of the foamed geopolymers were within $0.033-0.037 \mathrm{~W} / \mathrm{m}-\mathrm{K}$ for all foamed geopolymer samples tested which is a significant reduction compared to the thermal conductivity of the unfoamed geopolymer sample at $0.48 \mathrm{~W} / \mathrm{m}-\mathrm{K}$. The fire resistance tests show that the unfoamed geopolymer samples perform better than OPC concrete. However, the foamed geopolymers have very low strength compared to the unfoamed sample compressive strength of $18.1 \mathrm{MPa}$ and, thus, are suitable for non-load bearing, insulation applications.
\end{abstract}

Keywords: Fire resistance, Foaming agents, Geopolymers, Sustainability, Waste utilization

\section{Introduction}

In this study, three sustainability issues are relevant: (i) the reduction in the use of natural resources via industrial waste utilization in the production of geopolymers; (ii) the reduction in greenhouse gas (GHG) emissions via geopolymer production vis-à-vis OPC production; and (iii) the reduction of energy consumption in space cooling with the use of low heat transmission geopolymer-based building materials.

Considering the first and second issues, it is known that the building sector has been dominated by ordinary Portland cement (OPC) for more than a century that OPC has become the second most consumed commodity in the world - second only to water [3]. But 
OPC production has high GHG emissions and energy consumption and causes the depletion of natural resources, such as limestone, sand, and clay, among others. Thus, it is the OPC-based building sector that is presented with the environmental issues, while geopolymers have been shown to be comparable if not better than OPC in terms of technical properties and having as much as $80 \%$ less $\mathrm{CO}_{2}$ emissions in its production [4]. Moreover, sustainability is accessible since geopolymers can be formed from alumina- and silica- rich industrial wastes such as coal ash, mine tailings, furnace slag, etc. [5].

On the benefit of waste utilization, the major impact in the Philippines is conceivably in coal ash management. As of 2018, the Philippine Department of Energy (DOE) reported a total coal consumption of 30.8 MMT of which $84.6 \%$ was utilized by coal-fired power plants and from which 3.1 MMT of coal ashes were generated [6]. This is expected to rise as more coal-fired power plants are being built in the country [7].

On the third issue, the United Nations Environment Programme - Sustainable Buildings and Climate Initiative (UNEP-SBCI) recognizes that the building sector utilizes "about $40 \%$ of global energy, $25 \%$ of global water, $40 \%$ of global resources, and emit approximately $1 / 3$ of GHG emissions" and "yet, buildings also offer the greatest potential for achieving significant GHG emission reductions, at least cost, in developed and developing countries" and that "energy consumption in buildings can be reduced by 30 to $80 \%$ using proven and commercially available technologies" [8].

The Philippines is in the Tropics with hot and humid climates. As such the use of space cooling has become a necessity for the thermal comfort and productivity of occupants. As space cooling requirements increase with heat transmission across the building envelope, a better if not comparable alternative low heat transmission material should provide a positive impact towards decreasing the energy consumption associated with the space cooling in buildings [9].

Thus, the emergence of geopolymer technology advances a way to address these three sustainability issues at the same time. Geopolymers are now considered as the next-generation cement but with lower energy requirements and lower GHG emission while using aluminasilica- rich industrial wastes as raw materials [10-12].

In this study, geopolymers were formed using coal ashes and rice hulls waste materials, two dominant local waste materials in terms of volume generated in the Philippines. In a local study [1], different mix proportions of coal ashes and rice hull ash, as the aluminosilicate materials, were activated using $\mathrm{NaOH}-\mathrm{Na}_{2} \mathrm{SiO}_{3}$ solutions. The study obtained an optimum ternary mix proportion of $85 \%$ coal fly ash (CFA) - 10\% coal bottom ash (CBA) - 5\% rice hull ash (RHA), wt/wt, using a multiple response - RSM (response surface methodology) subject to the desirability conditions of minimum thermal conductivity, minimum density and compressive strength $\geq 11.7 \mathrm{MPa}$ targeting lightweight, low heat transmission, moderately load bearing building materials following ASTM C90-14 and ASTM C0109/C0109M. This ternary mix proportion is notable as it encompasses the $80-90 \%$ fly ash to $10-20 \%$ bottom ash generation ratio during coal combustion for potential full coal ash utilization in geopolymer production. Typically, geopolymers are mostly fly ash-based with the bottom ash relegated to landfills. Rice hull ash was used as an additive since it contains a high percentage of silica [13] and its reaction with sodium hydroxide may increase the amount of sodium silicate which acts as the alkaline activator of the mixture $[13,14,15]$.

In this study, the characterization of the $85 \%$ CFA - 10\% CBA - 5\% RHA, wt/wt, mix proportion was extended to include measurements of fire resistance using ASTM E119 [2] and the further reduction of thermal conductivity by the use of foaming agents and their impact on strength and density. 


\section{Materials and Methods}

The average composition of the individual raw materials, CFA, CBA and RHA, obtained via $\mathrm{X}$-ray fluorescence (XRF) spectroscopy, in percentage by mass, is listed in Table 1. It is seen that the CFA and CBA are predominantly composed of alumina and silica with CFA having $66.5 \%$ silica and $21.75 \%$ alumina and the CBA having $57 \%$ silica and $18.40 \%$ alumina. As obtained from source, the RHA gave $70.1 \%$ silica content but with a loss on ignition of $28.64 \%$ which means that there is a significant amount of unburned carbon in it.

The dry mix of precursor materials is prepared using the $85 \% \mathrm{CFA}-10 \% \mathrm{CBA}$ $5 \%$ RHA, wt/wt, mix proportion. For the alkali activator solution, $12 \mathrm{M} \mathrm{NaOH}$ solution is mixed with waterglass $\left(\mathrm{Na}_{2} \mathrm{SiO}_{3}\right)$ solution $(55 \%$ water, modulus $=3)$ at an $80 \%$ to $20 \%$ mass ratio. The liquid alkali activator solution is then poured onto the dry mixture at 80 to 20 (wt/wt) solid-to-liquid ratio, stirred via electric mixers and poured onto molds.

Table 1. Composition of Raw Materials Using XRF

\begin{tabular}{cccc}
\hline & CFA & CBA & RHA \\
\hline $\mathrm{Al}_{2} \mathrm{O}_{3}$ & 21.75 & 18.40 & \\
$\mathrm{SiO}_{2}$ & 66.5 & 57.0 & 70.1 \\
$\mathrm{~K}_{2} \mathrm{O}$ & 1.49 & & 1.10 \\
$\mathrm{CaO}$ & 5.30 & 11.05 & 0.19 \\
$\mathrm{TiO}_{2}$ & 0.40 & 1.14 & \\
$\mathrm{Cr}_{2} \mathrm{O}_{3}$ & & 0.08 & \\
$\mathrm{Fe}_{2} \mathrm{O}_{3}$ & 2.52 & 10.50 & \\
$\mathrm{LOI}$ & 2.18 & 1.07 & 28.64 \\
\hline
\end{tabular}

For the fire resistance tests, $200 \mathrm{~mm}$ x $200 \mathrm{~mm}$ x $50 \mathrm{~mm}$ molds were used to form $50 \mathrm{~mm}$ thick slab type specimens. For the thermal conductivity and compressive strength tests, $50 \mathrm{~mm} \times 50 \mathrm{~mm} \times 50 \mathrm{~mm}$ cube molds were used.

For the specimens to be evaluated for the effect of foaming agents, two types of foaming agents, hydrogen peroxide, $\mathrm{H}_{2} \mathrm{O}_{2}$, and sodium perborate, $\mathrm{Na}_{2} \mathrm{~B}_{2} \mathrm{O}_{4}(\mathrm{OH})_{4}$, was added to the geopolymer slurry at $0.1 \%$ to $0.4 \%$ by mass of dry mix and then placed in the cubical molds.

All the geopolymer specimens were pre-cured for 24 hours at a slightly elevated temperature of $80^{\circ} \mathrm{C}$ in a convection oven and then cured at ambient temperature for 28 days. Upon curing, some samples were placed in a muffle furnace for 2 hours at $1000^{\circ} \mathrm{C}$.

The as-cured specimens and specimens exposed to $1000^{\circ} \mathrm{C}$ for 2 -hrs in a muffle furnace were analyzed using thermogravimetric analysis (TGA) to determine the range of thermal stability. Fourier transform infra-red spectroscopy (FTIR) was used on the geopolymer samples to determine the extent of geopolymerization. X-ray diffraction (XRD) and scanning electron microscopy (SEM) were used to evaluate the composition and micro-structure of the raw materials and geopolymer samples. Compressive strength was tested using an automatic uniframe compression tester and the thermal conductivity was measured using a thermal conductivity meter.

The tests for fire resistance were done based on the ASTM E119, Standard Test Methods for Fire Tests of Building Construction and Materials [2]. In the fire resistance test, one side of the slab samples was exposed to a fire inside an oven. The temperature inside the oven simulates the temperature vs. time profile as shown in Figure 1. This temperature profile 
is prescribed by ASTM E119 as a simulation of the temperature profile that occurs in an actual fire. According to this temperature vs. time profile, as the fire in a building progresses, after 5 minutes the temperature inside the building is $538^{\circ} \mathrm{C}$, after 10 minutes the temperature inside the building is $704^{\circ} \mathrm{C}$, and so on. The details of the temperature profile at selected points in exposure time are given in Table 2.

Table 2. Details of ASTM E119 Temperature Profile

\begin{tabular}{cc}
\hline Time & Temperature \\
\hline 5 minutes & $538^{\circ} \mathrm{C}$ \\
10 minutes & $704^{\circ} \mathrm{C}$ \\
30 minutes & $843^{\circ} \mathrm{C}$ \\
60 minutes & $927^{\circ} \mathrm{C}$ \\
120 minutes & $1010^{\circ} \mathrm{C}$ \\
\hline
\end{tabular}

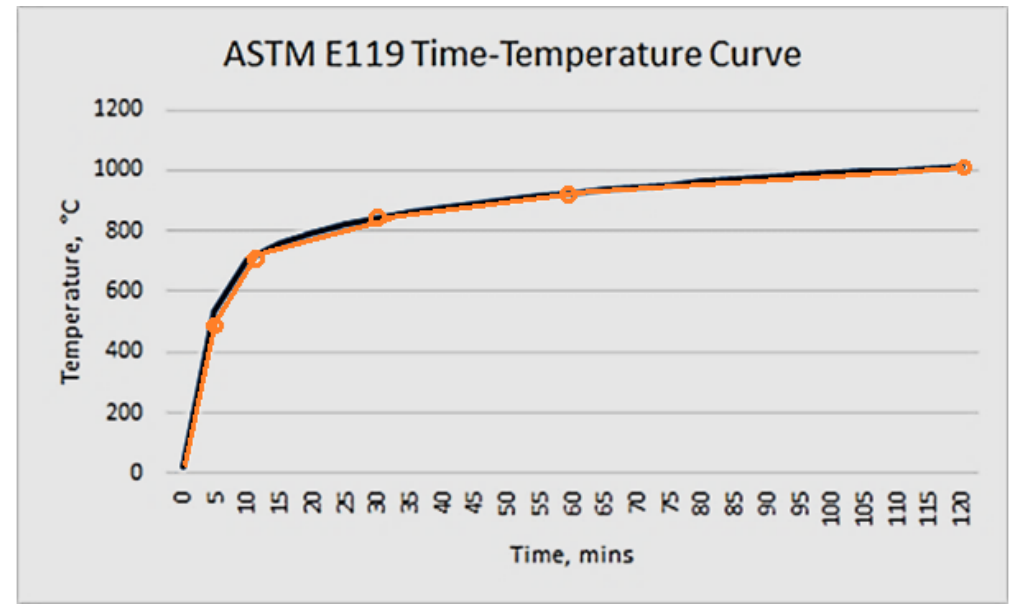

Figure 1. ASTM E119 fire resistance test temperature profile

Based on this standard, specimen failure is considered if the temperature of the unexposed surface of the sample rises an average of $140^{\circ} \mathrm{C}$ above its initial temperature. Visual cracking is also considered an indication of material failure due to fire exposure.

\section{Results and Discussion}

Figure 2 shows the TGA thermograph of the ternary mixture of the 85\% CFA - 10\% CBA $5 \%$ RHA. From the thermograph, there is a significant reduction in mass up until $110^{\circ} \mathrm{C}$ as seen from the green curve and associated with an endothermic process as seen from the blue curve. This is indicative of the loss of water and other volatiles via evaporation. This means that prior to heating, the geopolymer has a high water-retention which may be attributed to the high porosity and high unburned carbon content of the RHA as evidenced by its loss on ignition (LOI) of $28.64 \%$. From $350^{\circ} \mathrm{C}-435^{\circ} \mathrm{C}$, the peak in the heat flow curve (blue line) in the thermograph indicates an exothermic reaction which can be attributed to the combustion of the unburned carbon in the RHA. Davidovits [16] pointed out that this may result to the inhibition of the geopolymerization process due to unburned carbon content. It is noted that geopolymers with only small amounts of RHA will not demonstrate these events and will be thermally stable within the temperature range used for the test (ambient up to $800^{\circ} \mathrm{C}$ ). Thermographs of geopolymer samples exposed to $1000^{\circ} \mathrm{C}$ for two hours show both chemical and thermal stability for the given temperature range as shown in Figure 3. 
In the XRD analyses, Figure 4 shows the diffractograms of the individual raw materials. The peaks in the diffractograms between 20 to 30 (theta degree) indicates crystalline silica in the form of quartz however the spectrum of the RHA with one broad hump peak between 15 to 25 (theta degree) indicates amorphous silica which is the more reactive form of silica in the geopolymerization process [16, 17]. Figure 5 shows the diffractogram of the $85 \%$ CFA - 10\% CBA - 5\% RHA, which clearly shows the presence of the same quartz structure of silica indicative of unreactive silica.

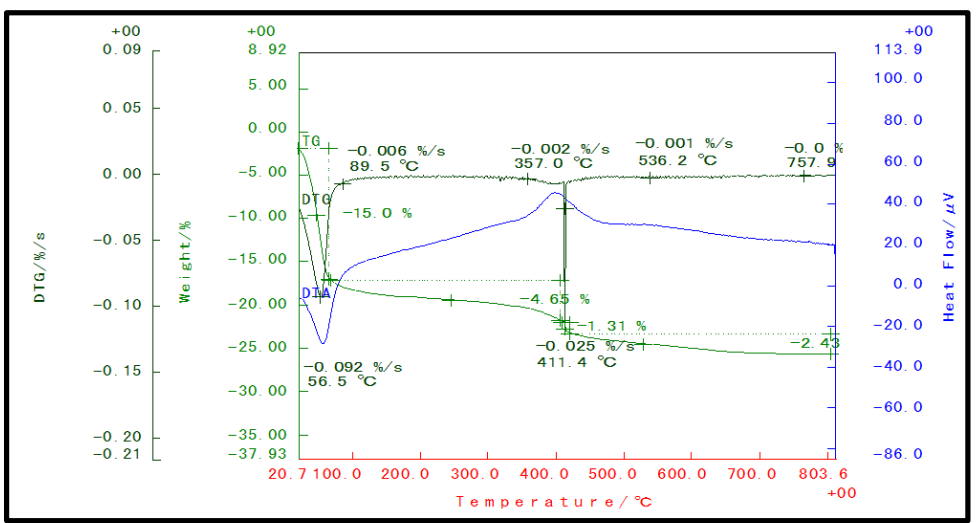

Figure 2. Sample TGA thermograph of an unfoamed geopolymer containing RHA

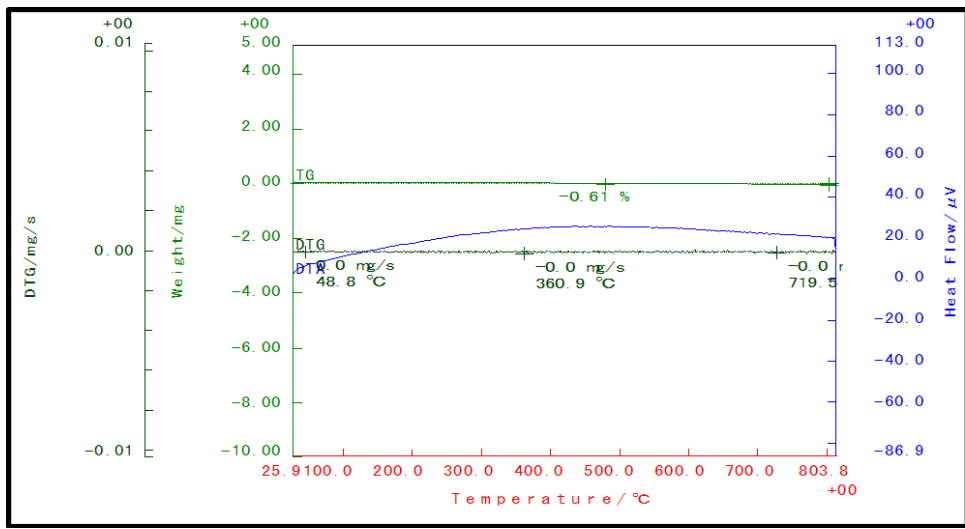

Figure 3. Sample thermograph of geopolymer after exposure to $1000^{\circ} \mathrm{C}$ for 2 hours

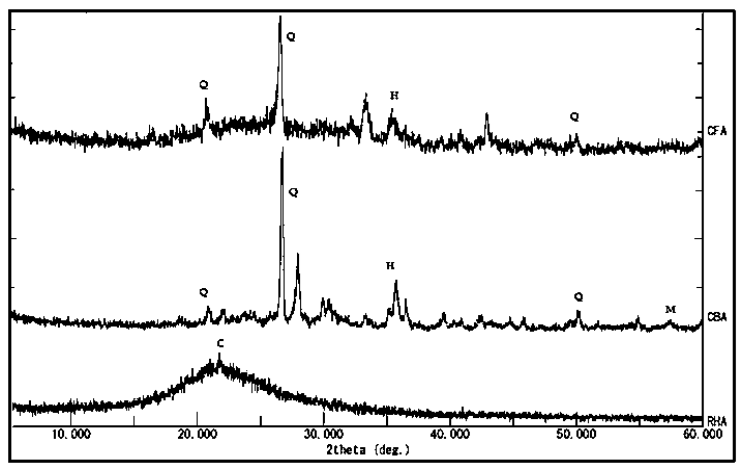

Figure 4. XRD diffractogram of the local raw materials, CFA, CBA and RHA.Legend:

$\mathrm{C}$,cristobalite-SiO $\mathrm{Si}_{2} ; \mathrm{Q}$, quartz-SiO $2 ; \mathrm{H}$, hematite; $\mathrm{M}$, magnetite. Reprinted from "Optimizing and characterizing geopolymers from ternary blend of Philippine coal fly ash, coal bottom ash and rice hull ash," by M. E. Kalaw, M.A. Promentilla et al, 2016, Materials, Vol. 9, Issue 7 


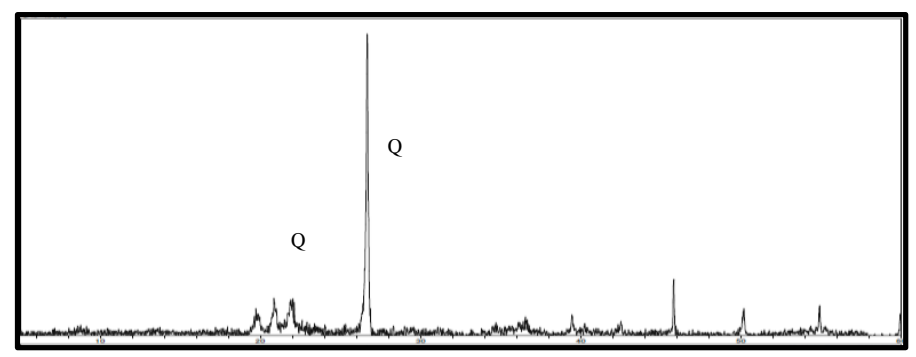

Figure 5. XRD diffractogram of the $85 \%$ CFA - 10\% CBA - 5\% RHA geopolymer

In the FTIR spectra of the individual raw materials, as shown in Figure 6, all raw materials show $\mathrm{H}-\mathrm{O}-\mathrm{H}$ bond stretching and bending at around $3440 \mathrm{~cm}^{-1}$ indicative of the presence of water. The Si-O-Si, Si-O- bondings were observed at $1080 \mathrm{~cm}^{-1}$. Si-O, Si-O-Al bondings were seen at $794 \mathrm{~cm}^{-1}$. Si-O-Fe were seen at $467 \mathrm{~cm}^{-1}$. These supports the components of the raw materials identified in the XFR composition.

The FTIR spectrum of the $85 \%$ CFA - 10\% CBA - 5\% RHA geopolymer sample is shown in Figure 7. The $\mathrm{H}-\mathrm{O}-\mathrm{H}$ bond stretching and bending were still observed at wavenumber of $3450 \mathrm{~cm}^{-1}$. However, the $\mathrm{Si}-\mathrm{O}-\mathrm{Si}, \mathrm{Si}-\mathrm{O}$ - bondings at $1080 \mathrm{~cm}^{-1}$ in the raw materials have now disappeared as the $\mathrm{Si}-\mathrm{O}$ bonds are broken during the dissolution process and re-formed into Si-O-Al bondings at $794 \mathrm{~cm}^{-1}$ and Si-O-Fe at $467 \mathrm{~cm}^{-1}$ indicating their presence in the geopolymer formed. The unreacted $\mathrm{Si}-\mathrm{O}$ have shifted into lower energy bonds at $1018 \mathrm{~cm}^{-1}$. The presence of $\mathrm{Si}-\mathrm{O}-\mathrm{Al}$ is an indication that the geopolymerization process has taken place [18].

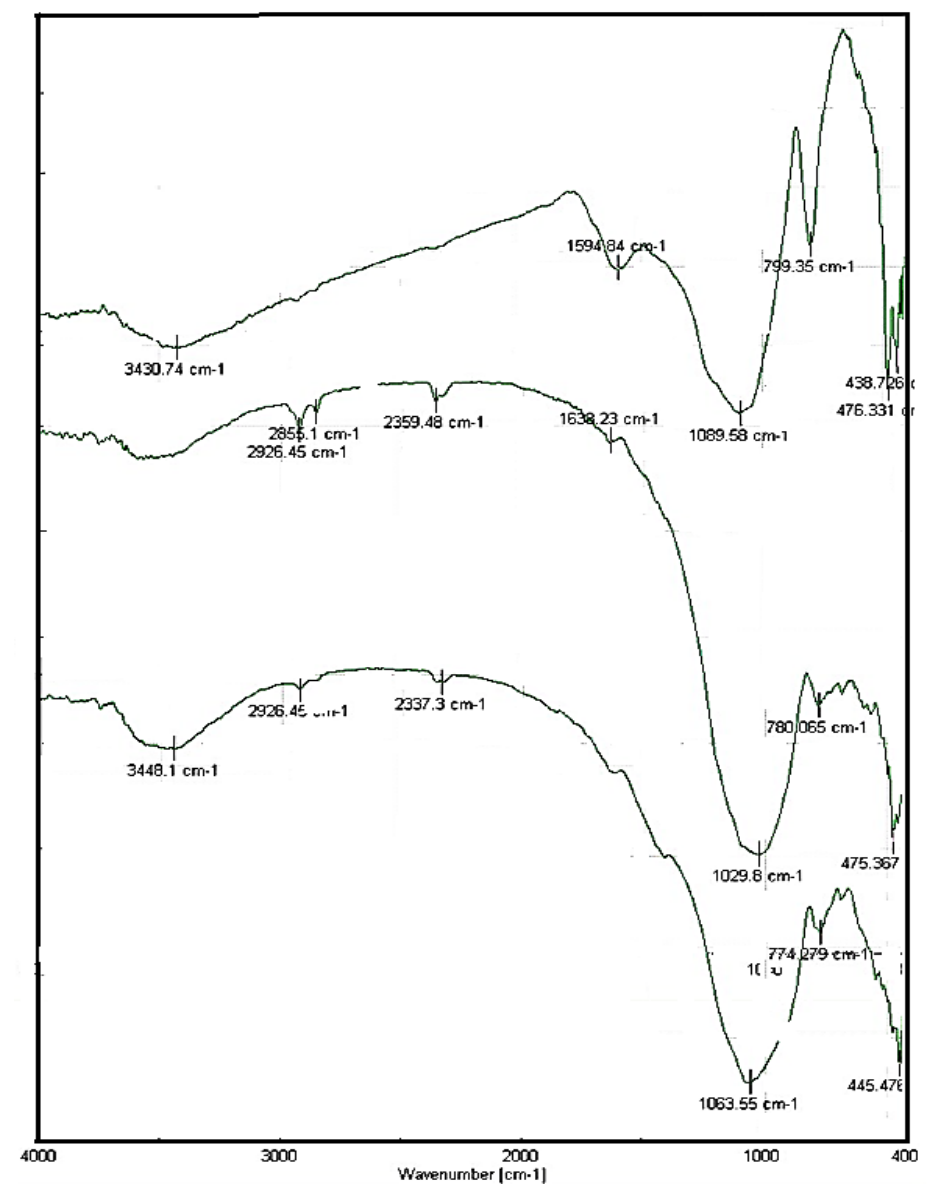

Figure 6. FTIR spectra of the individual raw materials 


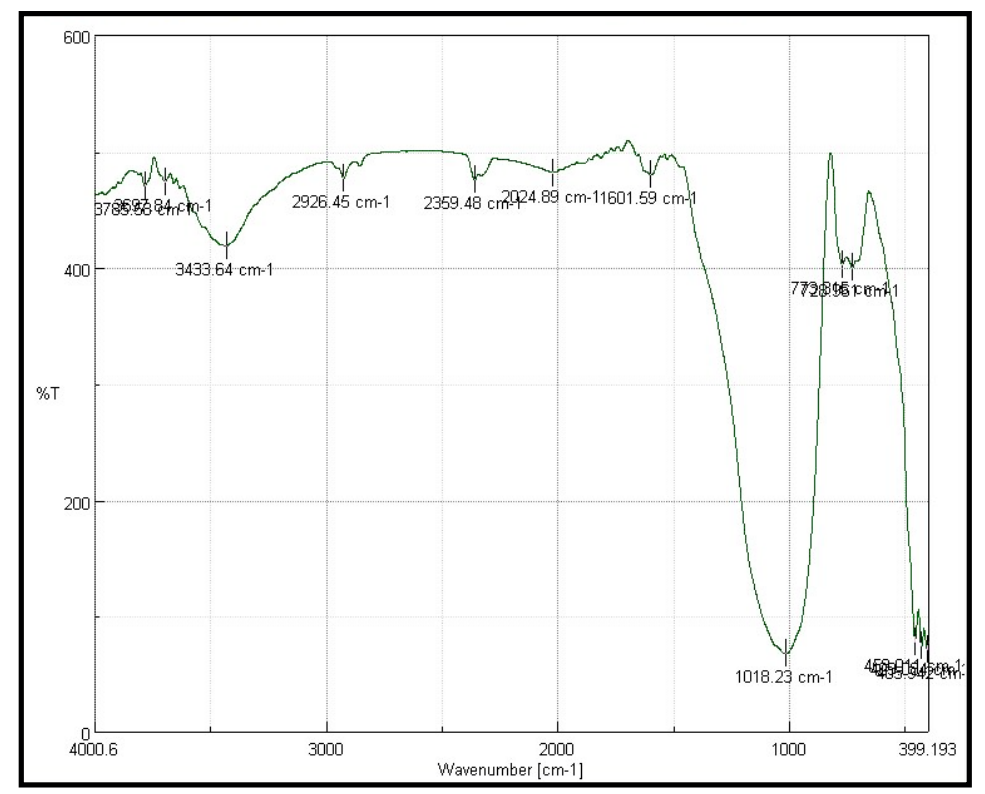

Figure 7. FTIR spectrum of 85\% CFA - 10\% CBA - 5\% RHA geopolymer sample

Figure 8 (a), (b) and (c) show the SEM micrographs of the individual raw materials. In Figure 8 (a), the micrograph is typical of CFA with spherical particles or globules which are known to be alumino-silicate spheres and iron rich spheres. As seen from the XRD and $\mathrm{XRF}$ analyses, these materials are present in the CFA. Figure 8 (b) show the structure of the CBA as irregular shaped particles. As CBA initially consists of bigger and coarser granular particles, the CBA has to undergo grinding to smaller particles. In this study, upon grinding, the CBA particles are within $\leq 250 \mu \mathrm{m}$ in size. The bigger particles and void spaces, as seen in Figure 8 (c) of the SEM micrograph of the RHA sample, suggests the high porosity of RHA raw material.

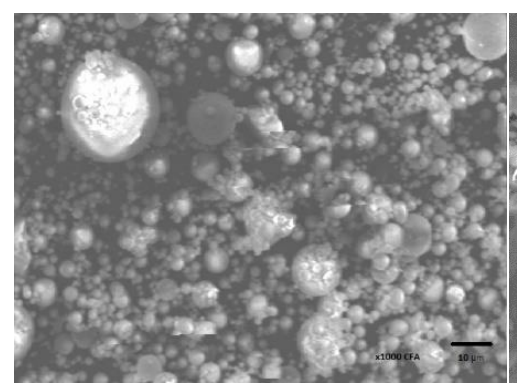

(a)

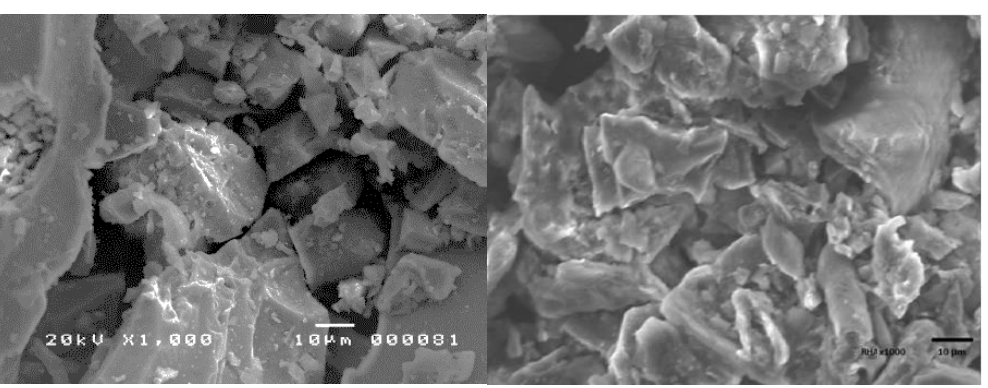

(b) (c)

Figure 8. SEM micrographs of the individual raw materials (a) CFA, (b) CBA and (c) RHA at 1000x magnification

The SEM micrograph of the geopolymer formed from the 85\% CFA - 10\% CBA 5\% RHA mix proportion is shown in Figure 9. In comparison with the SEM micrographs of the raw materials in Figure 8, the decreased sizes of particles indicate the extent of dissolution and subsequent polycondensation into geopolymers. However, the unchanged appearance of globules was indicative of poor geopolymerization reaction. As observed in the actual geopolymer preparation, more water is needed during mixing. This may be attributed to the silica and unburned carbon content, which are water adsorbent. XRF results show that the RHA is mostly amorphous silica and also has a $28.64 \%$ LOI. 


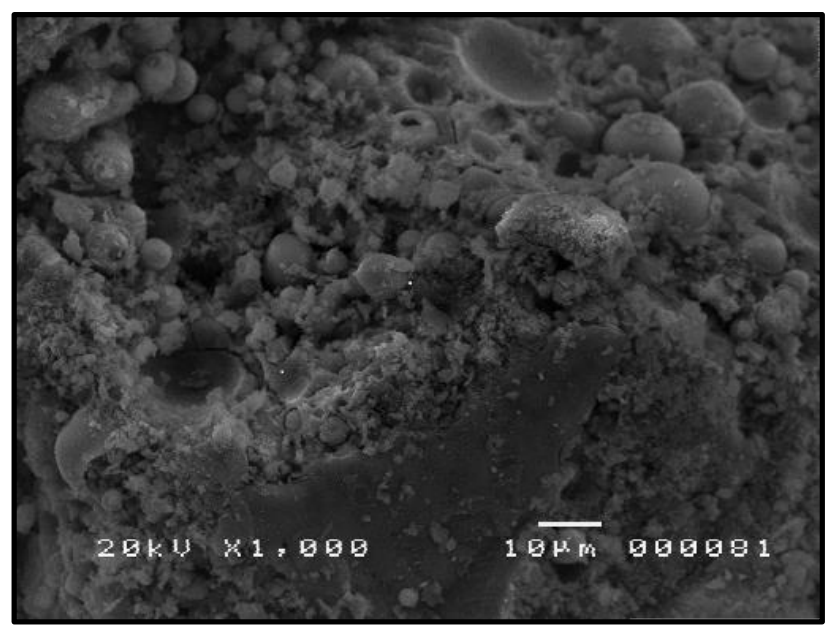

Figure 9. SEM micrograph of the 85\% CFA - 10\% CBA - 5\% RHA geopolymer sample (unfoamed).

The addition of foaming agents was done to induce pore formation in the geopolymer. This is expected to result in lower thermal conductivity and lower density but at decreased strength. The SEM micrograph in Figure 10 shows the microstructure of the $85 \%$ CFA - $10 \%$ CBA - 5\% RHA geopolymer with $0.3 \% \mathrm{wt} / \mathrm{wt}$ of sodium perborate foaming agent added. The bigger pores of the foamed geopolymer are evident from the micrograph in Figure 10 but the abundant globules with undiminished size show minimal geopolymerization process resulting in unreacted precursor materials.

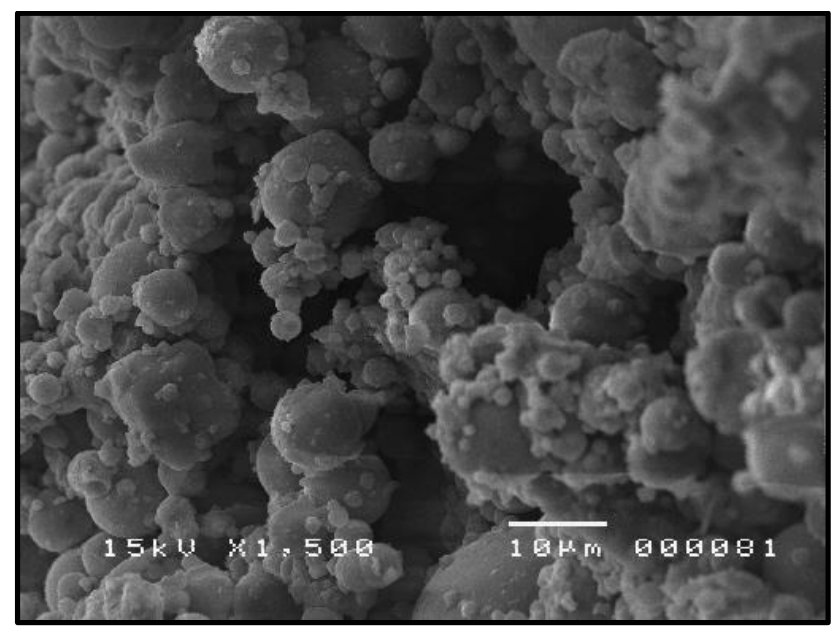

Figure 10. SEM micrograph of the $85 \%$ CFA - $10 \%$ CBA - 5\% RHA geopolymer sample (foamed with $0.3 \% \mathrm{wt} / \mathrm{wt}$ sodium perborate)

Table 3 gives a summary of the density, thermal conductivity and compressive strength of the geopolymer samples. ASTM C90-14, Standard Specification for Loadbearing Concrete Masonry Units [19] specifies a compressive strength greater than $11.7 \mathrm{MPa}$ and a volumetric weight less than $1680 \mathrm{~kg} / \mathrm{m}^{3}$ for lightweight, moderate load bearing concrete. The American Concrete Institute [20] estimates the thermal conductivity of concrete to be around $0.54 \mathrm{~W} / \mathrm{m}-\mathrm{K}$ at a volumetric weight of $1620 \mathrm{~kg} / \mathrm{m}^{3}$ and $0.67 \mathrm{~W} / \mathrm{m}-\mathrm{K}$ at a volumetric weight of $1792 \mathrm{~kg} / \mathrm{m}^{3}$. Thus, for this range of applications, only the unfoamed $85 \%$ CFA - 0\% CBA - 5\% RHA geopolymer has the strength and thermal conductivity that meet these requirements. 
With foaming agents, strength values are very low but the geopolymer samples are more lightweight and with very low thermal conductivity. Results gave compressive strength values ranging from 0.37 to $0.71 \mathrm{MPa}$ and densities of $1430-1560 \mathrm{~kg} / \mathrm{m}^{3}$ at $0.3 \%$ to $0.4 \%$ foaming agent (wt/wt) added. Values of thermal conductivity are within $0.033-0.037 \mathrm{~W} / \mathrm{m}$ $\mathrm{K}$ for all samples tested.

The fire resistance tests were conducted on $50 \mathrm{~mm}$ thick unfoamed geopolymer specimens including pure CFA geopolymers. The reference values are the tests done on pure OPC mortar and 1:2:3 ratio of OPC concrete. The results of these tests are tabulated in Table 4 and Table 5. The reduction in strength of the geopolymers is caused by the development of microcracks due to the dryness and shrinkage of the geopolymer as it is exposed to fire but the geopolymer network is still intact to retain a significant residual strength [21]. From these results, the geopolymer samples obtained higher fire resistance ratings (FRR) than similar OPC samples and with significantly higher residual strength. Figure 11 also shows that the unfoamed geopolymer samples are essentially intact after exposure to fire.

Table 3. Thermal Conductivity, Density and Compressive Strength of 85\% CFA 10\% - 5\% RHA Unfoamed and Foamed Geopolymers

\begin{tabular}{ccccc}
\hline $\begin{array}{c}\text { Foaming } \\
\text { Agent }\end{array}$ & $\%$ by dry mass & $\begin{array}{c}\text { Thermal } \\
\text { Conductivity } \\
(\mathbf{W} / \mathbf{m}-\mathbf{K})\end{array}$ & $\begin{array}{c}\text { Compressive } \\
\text { Strength } \\
(\mathbf{M P a})\end{array}$ & $\begin{array}{c}\text { Density } \\
\left(\mathbf{k g} / \mathbf{m}^{\mathbf{3}}\right)\end{array}$ \\
\hline Unfoamed & & 0.480 & 18.1 & 1850 \\
\hline Peroxide & 0.1 & 0.037 & 0.49 & 1810 \\
& 0.2 & 0.033 & 0.43 & 1860 \\
& 0.3 & 0.034 & 0.71 & 1440 \\
& 0.4 & 0.037 & 0.45 & 1540 \\
\hline Perborate & 0.1 & 0.033 & 0.50 & 1820 \\
& 0.2 & 0.034 & 0.37 & 1850 \\
& 0.3 & 0.033 & 0.42 & 1430 \\
& 0.4 & 0.037 & 0.40 & 1560 \\
\hline
\end{tabular}

Table 4. Fire Resistance Rating (FRR) of Unfoamed Samples.

\begin{tabular}{ccc}
\hline Sample (50mm) & Mixture & FRR Minutes \\
\hline Geopolymer & $85 \%$ CFA $-10 \%$ CBA -5\% RHA & 65 \\
\hline Cement & mortar (pure) & 35 \\
\hline Concrete & $1: 2: 3$ & 31 \\
\hline
\end{tabular}

Table 5. Compressive Strength Before and After Fire Exposure.

\begin{tabular}{cccc}
\hline Specimen & $\begin{array}{c}\text { Compressive } \\
\text { Strength, MPa } \\
\text { (Unfired) }\end{array}$ & $\begin{array}{c}\text { Compressive } \\
\text { Strength, MPa } \\
\text { (Fired) }\end{array}$ & $\begin{array}{c}\text { \% Residual } \\
\text { Strength }\end{array}$ \\
\hline Pure Cement & 12.49 & 3.27 & $26.2 \%$ \\
$\begin{array}{c}\text { 100\% CFA geopolymer } \\
\text { 85\% CFA -10\% CBA - 5\% RHA } \\
\text { geopolymer }\end{array}$ & 19.09 & 18.3 & $95.9 \%$ \\
\hline
\end{tabular}




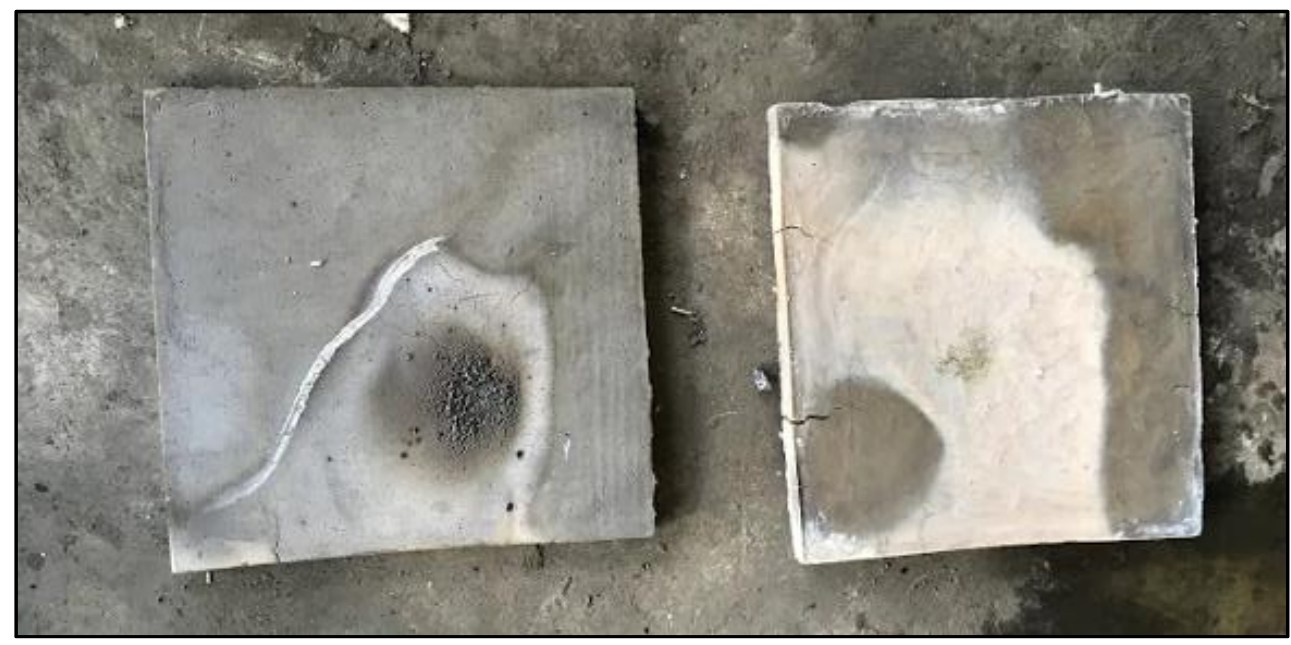

Figure 11. Geopolymer samples after fire resistance test

\section{Conclusions}

Based on the results of this study, the following conclusions are made:

1. Lightweight, low thermal conductivity, with moderate strength and having good fire resistance geopolymers can be developed from the $85 \%$ CFA - 10\% CBA $5 \%$ RHA wt/wt mix proportion and with sodium hydroxide-sodium silicate $\left(\mathrm{NaOH}-\mathrm{Na}_{2} \mathrm{SiO}_{3}\right)$ solution as alkali activator.

2. Using foaming agents significantly reduces the thermal conductivity and volumetric weight of the geopolymers formed, however, the strength is markedly reduced.

3. However, based on the comparisons of the XRD, FTIR and SEM analyses of the individual raw materials and the foamed and unfoamed geopolymers, the level of geopolymerization achieved is very low.

4. For the unfoamed samples, the geopolymer properties obtained are comparable to OPC concrete for lightweight, moderate load bearing structural applications with similar or better heat transmission characteristics. The foamed geopolymers formed, being very lightweight and having very low thermal conductivity may find applications as non-load bearing, insulation materials.

5. The unfoamed geopolymers formed performed better in terms of fire resistance compared to similar samples of cement mortar and concrete.

Thus, the coal fly ash-based geopolymers, with raw material proportions and characteristics used in this study, show that their properties are comparable to conventional materials such as concrete. As such, they can be practical and sustainable building materials. Further research to improve properties and to mass commercialization may lead to large-scale utilization in the future and may ultimately result in helping to alleviate the environmental impact of coal ash generation in the Philippines.

\section{Acknowledgement}

The authors acknowledge the Hinode Laboratory of the IDE Department of Tokyo Institute of Technology for the use of their facilities, JICA and AUN/SEEDNet for financial and technical support, the De La Salle University ME and CIV Laboratories, and the DLSU undergraduate thesis group of Alfred Relucio, Melvin Lim, Paul Palaypayon and Timothy Ngo for conducting the fire resistance tests. 


\section{References}

[1] M.E. Kalaw, A. Culaba, H. Hinode, W. Kurniawan, S. Gallardo, and M.A. Promentilla, "Optimizing and characterizing geopolymers from ternary blend of Philippine coal fly ash, coal bottom ash and rice hull ash," Materials, Vol. 9, No. 7, Article 580, 2016. doi.org/10.3390/ma9070580

[2] American Society for Testing Materials, Standard Test Methods for Fire Tests of Building Construction and Materials (ASTM E119), ASTM International, West Conshohocken, Pennsylvania, United States, 2000.

[3] "CEMENT 101 - An introduction to the world's most important building material," Global Cement Magazine, Volume 2011, July-August Issue, August 2011 [Online]. Available: globalcement.com/magazine/articles/490-cement-101-an-introduction-tothe-worlds-most-important-building-material [Accessed: June 2019]

[4] J. Davidovits, "Properties of geopolymer cements," Paper presented at First International Conference on Alkaline Cements and Concretes, Scientific Research Institute on Binders and Materials, Kiev State Technical University, Kiev, Ukraine, 1994.

[5] C. Shi, A.F. Jiménez, and A. Palomo, "New cements for the $21^{\text {st }}$ century: The pursuit of an alternative to Portland cement," Cement and Concrete Research, Vol. 41, pp. 750$763,2011$.

[6] Department of Energy, "2018 Coal Consumption,” 2018 [Online]. Available: https://www.doe.gov.ph/energy-resources?q=energy-resources/coal-statistics [Accessed: September 2019]

[7] L. Lectura, “49 Power Projects Ready by 2019," Business Mirror, July 5, 2015 [Online]. Available: https://businessmirror.com.ph/2015/07/05/49-power-projects-ready-by2019.

[8] United Nations Environment Programme. "Energy Efficiency for Buildings," UNEP Info sheet - EE Buildings.pdf [Online].

Available: $\quad$ http://www.studiocollantin.eu/pdf/UNEP\%20Info\%20sheet\%20\%20EE\%20Buildings.pdf [Accessed: June 2019]

[9] R. Wimmer, "Adapting zero carbon houses for tropical climates - Passive cooling design in the Philippines," In: Proceedings SB13 - Sustainable Buildings, Infrastructures and Communities in Emerging Economies, Center for Appropriate Technology, Vienna, Austria, 2013.

[10] B. Singh, G. Ishwarya, M. Gupta, and S. Bhattacharyya, "Geopolymer concrete: A review of some recent developments," Construction and Building Materials, Vol. 85, pp. 78-90, 2015.

[11] P. Duxson, A. Fernandez-Jimenez, J. Provis, G. Lukey, A. Palomo, and J. van Deventer, "Geopolymer technology: the current state of the art," Journal of Material Science, Vol. 42, pp. 2917-2933, 2007.

[12] J. Provis, "Alkali-activated materials," Cement and Concrete Research, Vol. 114, pp. 40-48, 2018.

[13] U. Kalapathya, A. Proctor, and J. Shultz, "An improved method for production of silica from rice hull ash," Bioresource Technology, Vol. 85, pp. 285-289, 2002.

[14] H.K. Tchakouté, C.H. Rüscher, S. Kong, E. Kamseu, and C. Leonelli, "Geopolymer binders from metakaolin using sodium waterglass from waste glass and rice husk ash as alternative activators: A comparative study," Construction and Building Materials, Vol. 114, pp. 276-289, 2016.

[15] H.K. Tchakouté, C.H. Rüscher, S. Kong, E. Kamseu, and C. Leonelli, "Comparison of metakaolin-based geopolymer cements from commercial sodium waterglass and sodium waterglass from rice husk ash," Journal of Sol-Gel Science and Technology, Vol. 78, pp. 492-506, 2016. 
[16] J. Davidovits, Geopolymer Chemistry and Applications, $3^{\text {rd }}$ Edition, Institut Géopolymère, France, 2011.

[17] R. Siddique, and M.I. Khan, Supplementary Cementing Materials, Engineering Materials Series, Springer-Verlag, Berlin, Germany, 2011. doi: 10.1007/978-3-64217866-5_5

[18] G.F. Huseien, and J.Mirza, "Theory of geopolymer synthesis," In Theory and Applications of Geopolymer in Civil Engineering Construction, $1{ }^{\text {st }}$ Edition, M. Ismail, M. Azreen, and M. Ariffin, eds.: Penerbit UTM Press, Malaysia, 2016.

[19] American Society for Testing Materials, Standard Specification for Loadbearing Concrete Masonry Units (ASTM C90-14), ASTM International, West Conshohocken, Pennsylvania, United States, 2014.

[20] American Concrete Institute, Guide to Thermal Properties of Concrete and Masonry Systems (ACI 122R-02), Michigan, United States, 2002.

[21] X. Peng, H. Li, Q. Shuai, and L. Wang, "Fire resistance of alkali activated geopolymer foams produced from metakaolin and $\mathrm{Na}_{2} \mathrm{O}_{2}$," Materials, Vol. 13, No. 3, Article 535, 2020. https://doi.org/10.3390/ma13030535 